Open Access

\title{
A novel selective cooling system for the brain: feasibility study in rabbits vs piglets
}

\author{
Mohammad Fazel Bakhsheshi ${ }^{12^{*}}$, Lynn Keenliside ${ }^{1}$ and Ting-Yim Lee Le, $^{1,3}$
}

\author{
* Correspondence: \\ mfazelba@alumni.uwo.ca \\ ${ }^{1}$ Imaging Program, Lawson Health \\ Research Institute, London, Ontario, \\ Canada \\ ${ }^{2}$ Imaging Research Laboratories, \\ Robarts Research Institute, 100 \\ Perth Drive, P.O. Box 5015, London, \\ Ontario N6A 5k8, Canada \\ Full list of author information is \\ available at the end of the article
}

\begin{abstract}
Background: Selective brain cooling (SBC) methods could alleviate the complications associated with systemic hypothermia. The authors (MFB, LK, and T-YL) have developed a simple and an effective nasopharyngeal SBC method using a vortex tube. The primary focus of the study is to evaluate the effectiveness of this approach on rabbits and compare it with our previous published finding on piglets, which are mammals without and with a carotid rete, respectively.
\end{abstract}

Methods: Experiments were conducted on six rabbits. Body temperature was measured continuously using an esophageal temperature probe while brain temperature was measured with an implanted thermometer. Two successive experiments were performed on each animal. In the first experiment, brain cooling was initiated by blowing room temperature air from the hospital medical air outlet, at a flow rate of 14-15 L/min into both nostrils for $60 \mathrm{~min}$. The second series of measurements and brain cooling was performed in the same manner as the first one but blowing cold air $\left(-7^{\circ} \mathrm{C}\right)$ at the same flow rate.

Results: One hour post cooling with room temperature air at a flow rate of 14-15 L/min, the brain temperature was $34.2 \pm 1.2{ }^{\circ} \mathrm{C}$ which resulted in mean brain cooling rates of $3.7 \pm 0.9^{\circ} \mathrm{C} / \mathrm{h}$. Brain temperature could be reduced more rapidly at mean rates of $5.2 \pm 1.9^{\circ} \mathrm{C} / \mathrm{h}$, while the body temperature as measured by the esophageal temperature probe was maintained above $36{ }^{\circ} \mathrm{C}$ during cooling and maintaining period.

Conclusions: We have demonstrated that using the vortex tube allows initial rapid and SBC in rabbits. Moreover, comparing results between piglets and rabbits demonstrates clearly that the lack of a carotid rete does not prevent specific cooling of the brain by means of the nasopharyngeal method.

Keywords: Brain temperature, Se brain cooling, Vortex tube, Rabbit, Nasopharyngeal brain cooling, Carotid rete

\section{Introduction}

Therapeutic hypothermia has become an effective neuroprotective strategy as it can inhibit multiple pathways involved in ischemia/reperfusion injury [1-3]. Although some clinical studies indicate that the temperature range associated with better outcomes appears to be 32 to $35^{\circ} \mathrm{C}[4,5]$, a recent study revealed no significant difference between hypothermic and near-normothermic treatment groups $\left(33^{\circ} \mathrm{C}\right.$ and $\left.36{ }^{\circ} \mathrm{C}\right)$ in patients after cardiac arrest in terms of their survival and neurologic outcome [6]. Currently, most brain cooling methods rely on cooling down the whole body; however, decreasing

(c) The Author(s). 2018 Open Access This article is distributed under the terms of the Creative Commons Attribution 4.0 International License (http://creativecommons.org/licenses/by/4.0/), which permits unrestricted use, distribution, and reproduction in any medium, provided you give appropriate credit to the original author(s) and the source, provide a link to the Creative Commons license, and indicate if changes were made. 
the whole-body temperature below $34{ }^{\circ} \mathrm{C}$ can induce severe complications [7-9]. Therefore, selective rapid brain cooling and temperature control is beneficial to implement than whole-body cooling. To achieve this goal, different selective brain cooling (SBC) methods have been investigated to minimize the complications associated with systemic hypothermia by selectively cooling the brain. However, the limitations of the existing cooling technologies such as insufficient cooling and use of a relatively expensive coolant and/or irritant effects on skin contact points translate to their relative lack of effectiveness for the clinical conditions.

Cooling the nasal cavities lowers brain temperature due to the anatomic proximity of the internal carotid artery to the cavernous sinus [10]. Feasibility of intranasal evaporative cooling by RhinoChill device was successfully tested in patients after cardiac arrest $[11,12]$. In the PRINCE trial, the RhinoChill was able to decrease tympanic (as a surrogate of the brain) temperature in patients to $34.2^{\circ} \mathrm{C}$ in $\sim 34 \mathrm{~min}$ [13]. Likewise, in a recent study [14], this has also been confirmed in stroke patients $\left(-1.2^{\circ} \mathrm{C}\right.$ after $\left.58 \mathrm{~min}\right)$. The RhinoChill device vaporizes perfluorocarbon along with oxygen at a flow rate of 40-60 L/min with a catheter system into the nasal cavity leading to a fast induction of hypothermia. However, because prevention of brain injury may require up to $12-24 \mathrm{~h}$ of brain cooling, the cost for the coolant will be prohibitive if Rhinochill is used. Recently [15], we demonstrated a simple nasopharyngeal brain cooling method for lowering brain temperature based on blowing air into the nostrils at different temperatures and flow rates in a pig model [15]. However, mammals like pigs possess a carotid rete (a set of small arteries) which is a vast vascular network arising from the carotids at the base of the brain. The rete is surrounded by the cavernous sinus which receives cool blood from the nasal mucosa and face; together, these serve as an effective heat exchanger for the brain. In mammals with the carotid rete, arterial blood, on its way to the brain, is cooled in the carotid rete via heat exchange with cool venous blood returning from the nasal mucosa and face [16]. In mammals in which the carotid rete is missing (like in humans), some have suggested that there is no effective heat exchange in the cavernous sinus and, consequently, SBC is not efficient in these species [16]. Yet, several mammals, including horses, rabbits, and rats, lack a carotid rete but clearly demonstrate SBC [17-19]. To the best of our knowledge, there have been no previous studies comparing the efficiency of nasopharyngeal brain cooling on pigs and rabbits, which are mammals with and without a carotid rete, respectively.

The present study was an incremental work based on our previous research and was designed to evaluate the effectiveness of this approach on rabbits and compare it with our previously published findings on piglets [20, 21]. Maintenance of the brain-body temperature gradient following cooling was also explored.

\section{Materials and methods}

\section{Animal preparation and experimental procedure}

Experiments were conducted on six male New Zealand white rabbits, approximately 6 months old (weight $=3.5 \pm 0.2 \mathrm{~kg}$ ). All animal experiments were approved by the Animal Use Subcommittee of the Canadian Council of Animal Care at Western University. Animals were induced and maintained with isoflurane gas anesthesia at 4\% and $2-3 \%$ concentrations, respectively. The $4 \%$ isoflurane provided a rapid induction of 
anesthesia within $15-30 \mathrm{~s}$ while the $2-3 \%$ isoflurane maintained surgical anesthesia, allowing surgical procedures to be performed without any physiological signs of pain or changes of hemodynamic parameters. The animal was intubated with a cuffed endotracheal tube and ventilated with a volume-controlled mechanical ventilator to deliver oxygen/medical air mixture (2:1). Body temperature was measured continuously using an esophageal temperature probe attached to a Surgivet monitor (Temperature Probe WWV3418, Smiths Medical, Dublin, OH, USA). A 1-2-mm burr hole was drilled in the skull 1.5 posterior and 1.5 lateral to the bregma along the mid-line with a Dremel tool. The needle thermocouple probe (Digi-Sense, Type-K, Needle Microprobe, Mini Conn 0.75"L .020 Dia, GRD 5Ft FEP Cable) was inserted through the burr hole into the brain to a depth of $\approx 2 \mathrm{~cm}$ from the brain surface to measure brain temperature. A femoral artery was catheterized to monitor heart rate (HR) and mean arterial blood pressure (MAP) and to intermittently collect arterial blood samples for gas and electrolyte levels $\left(p_{a} \mathrm{CO}_{2}, p_{a} \mathrm{O}_{2}, \mathrm{~S}_{a} \mathrm{O}_{2}, c \mathrm{Na}^{+}, c \mathrm{~K}^{+}, c \mathrm{Cl}^{-}\right.$, and $\left.c \mathrm{Ca}^{2+}\right)$ and $\mathrm{pH}$ analyses. Arterial blood was drawn every $30 \mathrm{~min}$ to measure arterial blood gas with an analyzer (ABL80 FLEX CO-OX, Radiometer Medical ApS, DK-2700, Brønshøj, Denmark).

After surgery, each animal together with a recirculating hot water pad was wrapped with linen blankets, maintained on $2-3 \%$ isoflurane, and 30-40 min were allowed for baseline physiological parameters to stabilize before the nasopharyngeal brain cooling was started. Two successive experiments were performed on each animal. In the first experiment, nasopharyngeal brain cooling was initiated by blowing room temperature air $\left(21{ }^{\circ} \mathrm{C} \pm 1{ }^{\circ} \mathrm{C}\right.$ and relative humidity (RH) of $\left.15-20 \%\right)$, delivered from a hospital medical air outlet, at a flow rate of 14-15 L/min as measured by a flow meter (VWR Flow Meters Acrylic, FR4500 series with accuracy of $\pm 3 \%$, VWR International Inc) into both nostrils for $60 \mathrm{~min}$ (group I). The brain was then allowed to gradually rewarm to baseline temperature by turning off the hospital air supply. In the second experiment, brain cooling was accomplished by blowing cold air $\left(-7^{\circ} \mathrm{C}\right.$, RH $\left.15-20 \%\right)$ at the same flow rate as the first experiment for $60 \mathrm{~min}$. Once the brain temperature stabilized, the flow rate and air temperature were adjusted to maintain the brain temperature and reach for another $60 \mathrm{~min}$ while core body temperature was maintained above $36{ }^{\circ} \mathrm{C}$ using the recirculating hot water pad and by packing gloves filled with hot water around the body (group II). Cold air was generated by the vortex tube, as discussed in detail in the following section. During cooling, the mouth of the animal was kept open so that air can escape from mouth and nostrils.

Arterial $\mathrm{CO}_{2}$ tension $\left(p_{a} \mathrm{CO}_{2}\right)$ was monitored throughout the experiments, either directly by blood gas measurements or by the end-tidal $\mathrm{CO}_{2}$ tension $\left(\mathrm{EtCO}_{2}\right)$, and maintained at normocapnia between 37 and $42 \mathrm{mmHg}$ by adjusting the breathing rate and volume. $\mathrm{EtCO}_{2}$, tidal volume, respiratory rate, pulse oximetry $\left(\mathrm{SpO}_{2}\right)$, and heart rate were continuously measured using a multi-parameter monitor (Surgivet Advisor Vital Signs Monitor V9200, Smiths Medical, Dublin, OH, USA). Each experiment was completed in 8-9 h, and the animal was sacrificed with intravenous potassium chloride (1-2 $\mathrm{ml} / \mathrm{kg}, 2 \mathrm{mEq} / \mathrm{mL})$ infusion at the end of the experiments.

The experimental procedures used on piglets were similar to those used on rabbits $[20,22]$. These data are presented from our previous study in piglets [21]. Briefly, experiments were conducted on 12 piglets ( 7 females and 5 males) with an average age of $44 \pm 9 \mathrm{~h}$ and an average weight of $2.9 \pm 1.3 \mathrm{~kg}$. Following surgery, each piglet was 
wrapped with a linen blanket that was used to maintain the piglets normothermic at $38 \pm 0.5{ }^{\circ} \mathrm{C}$ for $60 \mathrm{~min}$ prior to the initiation of cooling. The temperature control was then discontinued, and the piglets were randomized to the following nasopharyngeal brain cooling treatments: room temperature at a flow rate of $14-15 \mathrm{~L} / \mathrm{min}(n=6)$ and $-7{ }^{\circ} \mathrm{C}$ at a flow rate of $14-15 \mathrm{~L} / \mathrm{min}(n=6)$. In all of the experimental studies, anesthesia was maintained with $1-2 \%$ isoflurane until the end of the experiment. Cold air was generated by circulating air, delivered from a pressurized tank, through a custom-made heat exchanger [20,22].

\section{Method of nasopharyngeal brain cooling}

The vortex tube (adjustable cold air gun, ITW Vortec Ltd), shown in Fig. 1, is a mechanical device that is used to generate cold air without any moving parts, chemical reactions, or external energy supply. Since the vortex tube contains no other parts inside the tube, the generation of an air streams at different temperature can only be attributed by the effects of fluid dynamics. Different hypotheses have been proposed for the basis of temperature separation. Nevertheless, a well-accepted explanation for the thermal phenomenon within the vortex tube has not been proposed due to the complex internal flow mechanism. Recently, an explanation was reported that the separation of

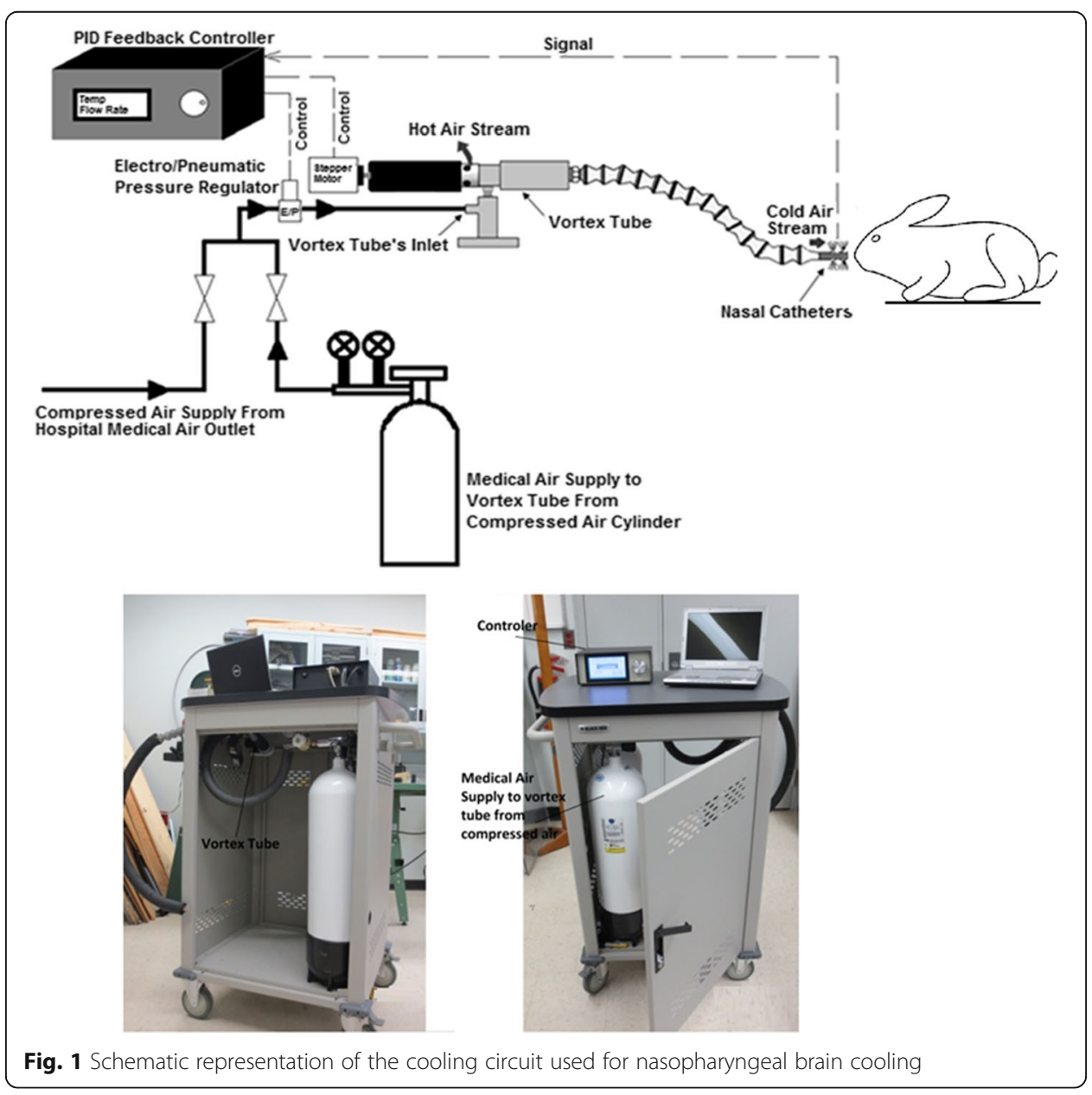


energy within a vortex tube was achieved by the turbulent eddies, which carry the heat from the core to the periphery [23]. However, the similarity between this explanation and the secondary circulation [24] and the lack of new evidence indicate the unclear mechanism within a vortex tube. In our study, a source of compressed medical air (supplied either by L'Air Liquide Ltd. in cylinders of capacity of $232 \mathrm{ft}^{3}$ at fill-pressure of 2265 PSI downregulated to 50 PSI or from a hospital medical outlet at a fixed outlet pressure of 50 PSI) is applied to the inlet nozzle. Air passes through the generation chamber of the vortex tube which creates the vortex inside the tube and separates the compressed air stream into cold and hot streams. The fraction of compressed air exiting as cold air (also referred as cold fraction) was adjusted by a throttle needle valve. aBoth the temperature and flow rate of the cold air stream are controlled and monitored continuously. The temperature at the cold air outlet was monitored and recorded continuously with a thermometer (Thermometer/Data Logger, HH309A, with Four Type K Thermocouple Inputs, Omega Engineering, Stamford CT; resolution $0.1{ }^{\circ} \mathrm{C}$ ). A thermistor was also placed inside one of the two nasal catheters to monitor the temperature of the cold air inside the nasal cavity throughout the experiments. Figure 1 shows the schematic of the experimental setup. Nasopharyngeal brain cooling was achieved by connecting the two nasal catheters (made from polyvinyl chloride, PVC) to the cold air outlet of a vortex tube via tubing. The nasal catheters were coated with $2 \%$ lidocaine gel for local anesthesia during insertion and were inserted $4-5 \mathrm{~cm}$ into each nostril.

\section{Statistical analysis}

SPSS 17.0.0 (SPSS, Inc., Chicago, IL) was used for all statistical analyses. Comparisons of vital signs were analyzed by two-way analysis of variance (ANOVA) with group and time as the two factors followed by post hoc test with Bonferroni correction to determine statistical differences at different times within a group and between groups at different times. Statistical significance was declared when $p$ value was $<0.05$. All numeric data are presented as mean \pm standard deviation (SD) unless otherwise noted.

\section{Results}

Table 1 displays a summary of the measured physiological parameters $\left(S_{a} \mathrm{O}_{2}, c \mathrm{Na}^{+}, c \mathrm{~K}^{+}\right.$, $c \mathrm{Cl}^{-}, c \mathrm{Ca}^{2+}, \mathrm{MAP}, \mathrm{HR}, \mathrm{pH}, P_{a} \mathrm{CO}_{2}$, and $\left.t \mathrm{Hb}\right)$ in the two groups, prior to and during cooling. There was no significant difference in any physiological parameter between the groups at baseline. In group I, $1 \mathrm{~h}$ after the initiation of cooling, when the mean brain temperature dropped to $34.5 \pm 0.9^{\circ} \mathrm{C}$, a statistically significant $(p<0.05)$ decrease in $\mathrm{HR}$ and MAP were observed, but $c \mathrm{~K}^{+}$started increasing after initiation of cooling. Similarly, in group II, there were statistically significant decreases in HR and MAP when the brain temperature dropped to $35.4 \pm 0.9^{\circ} \mathrm{C}$ and $33.2 \pm 1.2{ }^{\circ} \mathrm{C}$ after $30 \mathrm{~min}$ and $1 \mathrm{~h}$ of cooling, respectively, and remained significantly depressed (relative to baseline) for the duration of the study. As well, a statistically significant increase in $c \mathrm{~K}^{+}$was observed after $2 \mathrm{~h}$ of cooling. No arrhythmias were noted during cooling or rewarming. No incidences of catheter thrombosis, acute infection, or other complications associated with the insertion procedure were observed.

Changes in esophageal and brain temperatures in rabbits are shown in Fig. 2a. During the baseline monitoring period of 40-60 $\mathrm{min}$, both esophageal and brain temperature 
Table 1 Physiological parameters measured at different times during SBC within groups in rabbits

\begin{tabular}{|c|c|c|c|c|}
\hline \multirow{3}{*}{ Brain temperature $\left({ }^{\circ} \mathrm{C}\right)$} & \multirow{2}{*}{$\begin{array}{l}\text { Baseline } \\
1-60 \text { min }\end{array}$} & \multicolumn{3}{|l|}{ Cooling } \\
\hline & & \multirow[t]{2}{*}{$30 \mathrm{~min}$} & \multirow[t]{2}{*}{$1 \mathrm{~h}$} & \multirow[t]{2}{*}{$2 \mathrm{~h}$} \\
\hline & & & & \\
\hline Group I: $14-15 \mathrm{~L} / \mathrm{min}$ at RT & $38.2 \pm 0.7$ & $35.2 \pm 0.7^{*}$ & $34.5 \pm 0.9^{*}$ & N/A \\
\hline Group II: $14-15 \mathrm{~L} / \mathrm{min}$ at $-7^{\circ} \mathrm{C}$ & $37.8 \pm 0.4$ & $35.4 \pm 0.9^{*}$ & $33.2 \pm 1.2^{*}$ & $32.1 \pm 1.7^{*}$ \\
\hline \multicolumn{5}{|l|}{$\mathrm{S}_{\mathrm{a}} \mathrm{O}_{2}(\%)$} \\
\hline Group I: $14-15 \mathrm{~L} / \mathrm{min}$ at RT & 100 & 100 & 100 & N/A \\
\hline Group II: $14-15 \mathrm{~L} / \mathrm{min}$ at $-7^{\circ} \mathrm{C}$ & 100 & 100 & 100 & 100.0 \\
\hline \multicolumn{5}{|l|}{$\mathrm{CNa}^{+}(\mathrm{mmol} / \mathrm{L})$} \\
\hline Group I: $14-15 \mathrm{~L} / \mathrm{min}$ at RT & $141 \pm 3$ & $142 \pm 2$ & $142 \pm 3$ & $\mathrm{~N} / \mathrm{A}$ \\
\hline Group II: $14-15 \mathrm{~L} / \mathrm{min}$ at $-7^{\circ} \mathrm{C}$ & $144 \pm 2$ & $142 \pm 1$ & $141 \pm 1$ & $141 \pm 2$ \\
\hline \multicolumn{5}{|l|}{$\mathrm{CK}^{+}(\mathrm{mmol} / \mathrm{L})$} \\
\hline Group I: $14-15 \mathrm{~L} / \mathrm{min}$ at RT & $3.4 \pm 0.3$ & $3.5 \pm 0.2$ & $3.7 \pm 0.1$ & N/A \\
\hline Group II: $14-15 \mathrm{~L} / \mathrm{min}$ at $-7^{\circ} \mathrm{C}$ & $4.4 \pm 0.2$ & $4.5 \pm 0.5$ & $4.6 \pm 0.3$ & $5.1 \pm 0.3^{*}$ \\
\hline \multicolumn{5}{|l|}{$\mathrm{CCa}^{2+}(\mathrm{mmol} / \mathrm{L})$} \\
\hline Group I: $14-15 \mathrm{~L} / \mathrm{min}$ at RT & $1.2 \pm 0.1$ & $1.0 \pm 0.1$ & $1.3 \pm 0.1$ & N/A \\
\hline Group II: $14-15 \mathrm{~L} / \mathrm{min}$ at $-7^{\circ} \mathrm{C}$ & $1.1 \pm 0.1$ & $1.3 \pm 0.1$ & $1.2 \pm 0.1$ & $1.2 \pm 0.1$ \\
\hline \multicolumn{5}{|l|}{$\mathrm{cCl}^{-}(\mathrm{mmol} / \mathrm{L})$} \\
\hline Group I: $14-15 \mathrm{~L} / \mathrm{min}$ at RT & $102 \pm 2$ & $104 \pm 2$ & $102 \pm 2$ & N/A \\
\hline Group II: $14-15 \mathrm{~L} / \mathrm{min}$ at $-7^{\circ} \mathrm{C}$ & $110 \pm 3$ & $104 \pm 3$ & $103 \pm 1$ & $108 \pm 2$ \\
\hline \multicolumn{5}{|l|}{ MAP (mmHg) } \\
\hline Group I: $14-15 \mathrm{~L} / \mathrm{min}$ at RT & $37 \pm 6$ & $34 \pm 6$ & $30 \pm 5^{*}$ & N/A \\
\hline Group II: $14-15 \mathrm{~L} / \mathrm{min}$ at $-7^{\circ} \mathrm{C}$ & $35 \pm 4$ & $32 \pm 7$ & $27 \pm 6^{*}$ & $25 \pm 6^{*}$ \\
\hline \multicolumn{5}{|l|}{ HR (bpm) } \\
\hline Group I: $14-15 \mathrm{~L} / \mathrm{min}$ at RT & $272 \pm 20$ & $250 \pm 14^{*}$ & $226 \pm 16^{*}$ & N/A \\
\hline Group II: $14-15 \mathrm{~L} / \mathrm{min}$ at $-7^{\circ} \mathrm{C}$ & $275 \pm 11$ & $247 \pm 18^{*}$ & $215 \pm 20^{*}$ & $204 \pm 15^{*}$ \\
\hline \multicolumn{5}{|l|}{$\mathrm{pH}$} \\
\hline Group I: $14-15 \mathrm{~L} / \mathrm{min}$ at RT & $7.4 \pm 0.1$ & $7.4 \pm 0.1$ & $7.4 \pm 0.1$ & N/A \\
\hline Group II: $14-15 \mathrm{~L} / \mathrm{min}$ at $-7{ }^{\circ} \mathrm{C}$ & $7.4 \pm 0.1$ & $7.3 \pm 0.1$ & $7.3 \pm 0.1$ & $7.3 \pm 0.1$ \\
\hline \multicolumn{5}{|l|}{$\mathrm{tHb}(\mathrm{g} / \mathrm{dL})$} \\
\hline Group I: $14-15 \mathrm{~L} / \mathrm{min}$ at RT & $11.1 \pm 1.0$ & $12.2 \pm 0.8$ & $12.5 \pm 1.0$ & N/A \\
\hline Group II: $14-15 \mathrm{~L} / \mathrm{min}$ at $-7{ }^{\circ} \mathrm{C}$ & $12.4 \pm 1.0$ & $12.1 \pm 0.3$ & $12.4 \pm 0.9$ & $12.6 \pm 0.7$ \\
\hline \multicolumn{5}{|l|}{$\mathrm{paCO}_{2}(\mathrm{mmHg})$} \\
\hline Group I: $14-15 \mathrm{~L} / \mathrm{min}$ at RT & $38 \pm 2$ & $40 \pm 2$ & $37 \pm 2$ & N/A \\
\hline Group II: $14-15 \mathrm{~L} / \mathrm{min}$ at $-7^{\circ} \mathrm{C}$ & $37 \pm 2$ & $39 \pm 3$ & $40 \pm 1$ & $41 \pm 2$ \\
\hline
\end{tabular}

$\mathrm{SaO}_{2}$ oxygen saturation, MAP mean arterial blood pressure, $\mathrm{HR}$ heart rate, $t \mathrm{Hb}$ total hemoglobin in blood, $\mathrm{P}_{a} \mathrm{CO}_{2}$ arterial oxygen partial pressure, $\mathrm{CNa}^{+}$sodium concentration, $\mathrm{CK}^{+}$potassium concentration, $\mathrm{CCa}^{2+}$ calcium concentration, $\mathrm{CCl}^{-}$chloride concentration, $R T$ room temperature $\left(21^{\circ} \mathrm{C} \pm 1{ }^{\circ} \mathrm{C}\right), N / A$ not available

${ }^{*}$ A statistically significant $(p<0.05)$ difference compared to the baseline

did not vary more than $0.1 \pm 0.1{ }^{\circ} \mathrm{C}$ from the baseline. With the initiation of nasopharyngeal cooling with room temperature air at a flow rate of $14-15 \mathrm{~L} / \mathrm{min}$, the brain temperature decreased from $37.9 \pm 0.5^{\circ} \mathrm{C}$ to $35.6 \pm 0.9^{\circ} \mathrm{C}$ within $15 \mathrm{~min}$. One hour post cooling, the brain temperature reached $34.2 \pm 1.2{ }^{\circ} \mathrm{C}$ which resulted in a mean brain cooling rate of $3.7 \pm 0.9{ }^{\circ} \mathrm{C} / \mathrm{h}$, as displayed in Fig. 2a. The esophageal temperature decreased during the same interval from $38.3 \pm 0.3{ }^{\circ} \mathrm{C}$ to $36.2 \pm 0.6{ }^{\circ} \mathrm{C}$ which corresponded to a cooling rate of $2.1 \pm 0.4{ }^{\circ} \mathrm{C} / \mathrm{h}$. Figure $2 \mathrm{~b}$ shows the brain and esophageal 

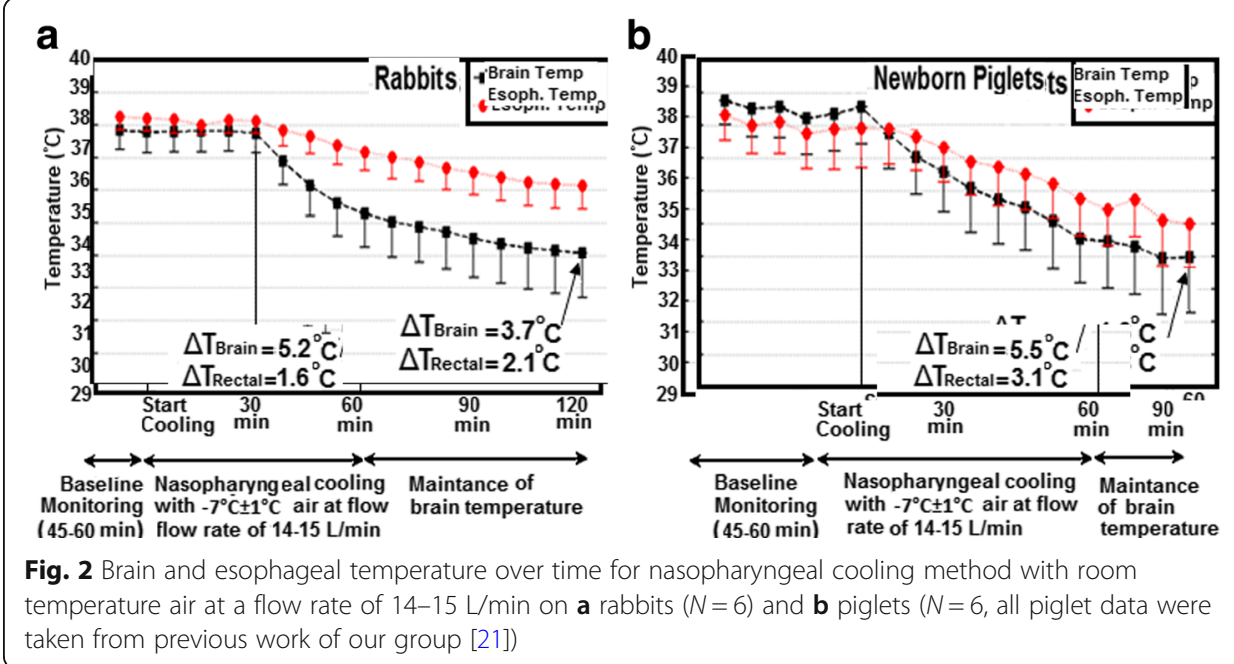

Fig. 2 Brain and esophageal temperature over time for nasopharyngeal cooling method with room temperature air at a flow rate of $14-15 \mathrm{~L} / \mathrm{min}$ on a rabbits $(N=6)$ and $\mathbf{b}$ piglets $(N=6$, all piglet data were taken from previous work of our group [21])

temperature as a function of time of piglets which underwent nasopharyngeal brain cooling in the same manner as the rabbits. Both brain and esophageal temperature decreased from $38.4 \pm 0.7{ }^{\circ} \mathrm{C}$ and $38.2 \pm 0.7{ }^{\circ} \mathrm{C}$ to $33.9 \pm 1.7^{\circ} \mathrm{C}$ and $35.4 \pm 1.7^{\circ} \mathrm{C}$. These changes in brain and esophageal temperatures corresponded to cooling rates of $4.5 \pm$ $1.2^{\circ} \mathrm{C} / \mathrm{h}$ and $2.8 \pm 0.6{ }^{\circ} \mathrm{C} / \mathrm{h}$, respectively, as displayed in Fig. $2 \mathrm{~b}$.

Following $60 \mathrm{~min}$ of cooling with room temperature air at a flow rate of $14-15 \mathrm{~L} / \mathrm{min}$, the air flow was stopped, and rewarming was initiated with the use of recirculating hot water pad and by packing gloves filled with hot water around the body of the animal. The return to the baseline pre-cooling temperature was usually achieved in $80 \pm 15 \mathrm{~min}$. During this phase, the brain and esophageal temperatures increased by $2.9 \pm 0.7^{\circ} \mathrm{C} / \mathrm{h}$ and $1.7 \pm 0.5^{\circ} \mathrm{C} / \mathrm{h}$, respectively. Temperatures in the rewarming period between the cooling episodes were not shown in Figs. 2 and 3.

Figure 3a shows that with the use of $-7{ }^{\circ} \mathrm{C}$ instead of room temperature air at the same flow rate, a faster cooling rate was achieved in rabbits. Mean brain and esophageal temperatures decreased to $32.3 \pm 2.1{ }^{\circ} \mathrm{C}$ and $36.5 \pm 0.5{ }^{\circ} \mathrm{C}$ within 60 min of cooling from baseline temperature of $37.5 \pm 0.8{ }^{\circ} \mathrm{C}$ and $38.1 \pm 0.3{ }^{\circ} \mathrm{C}$, which corresponded to
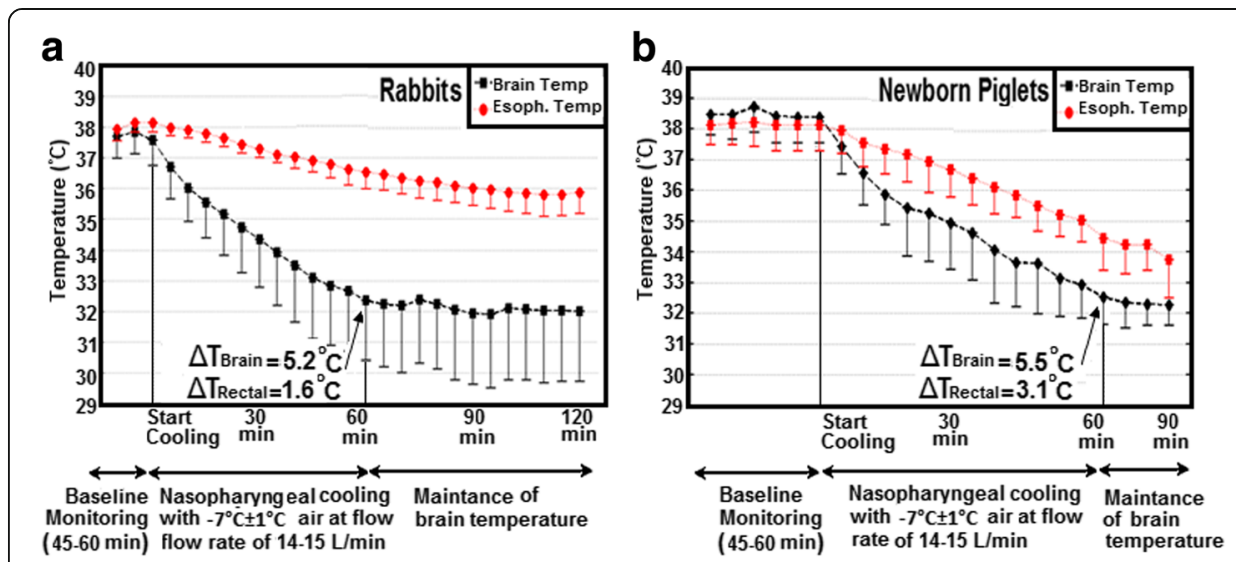

Fig. 3 Brain and esophageal temperature over time for nasopharyngeal cooling method with cold air at a flow rate of $14-15 \mathrm{~L} / \mathrm{min}$ on a rabbits $(N=6)$ and $\mathbf{b}$ piglets $(N=6$, all piglet data were taken from previous work of our group [21]) 
cooling rates of $5.2 \pm 1.9{ }^{\circ} \mathrm{C} / \mathrm{h}$ and $1.6 \pm 0.4{ }^{\circ} \mathrm{C} / \mathrm{h}$, respectively. The brain-body temperature gradient, calculated as the difference between brain and esophageal temperature, peaked about $55 \mathrm{~min}$ after the initiation of the cooling. This gradient could be maintained within $\pm 0.5^{\circ} \mathrm{C}$ for another hour by increasing the air temperature to $4 \pm 4{ }^{\circ} \mathrm{C}$ and adjusting the air flow rate to $20 \pm 10 \mathrm{~L} / \mathrm{min}$. Similarly, in piglets, Fig. 3b shows that brain and esophageal temperatures were reduced more rapidly at a rate of $5.5 \pm 1.1{ }^{\circ} \mathrm{C} / \mathrm{h}$ and $3.1 \pm 1.1{ }^{\circ} \mathrm{C} / \mathrm{h}$ by using $-7^{\circ} \mathrm{C}$ instead of room temperature air at the same flow rate.

Figure 4 shows the average brain cooling rates achieved using the nasopharyngeal brain cooling method with either room temperature or cold air at a flow rate of 14$15 \mathrm{~L} / \mathrm{min}$ for rabbits and piglets. Brain cooling rate was significantly greater with cold than room temperature air in both species. The brain cooling rates achieved in rabbits and piglets using the nasopharyngeal cooling method with either cold or room temperature air were not significantly different.

\section{Discussion}

The presented study has demonstrated that blowing cold air produced by the vortex tube into nasal cavities is an effective method to specifically reduce brain temperature and maintain it at such level in rabbits. In both animal species, nasopharyngeal brain cooling was accomplished by blowing room or cold air temperature into the nostrils at a flow rate of 14-15 L/min. The only difference in the source of cold air is as follows: for the rabbit experiments, the cold air was produced with a vortex tube whereas for the piglet experiments, cold air was from an in-house heat exchanger. In rabbits, brain cooling at the rate of $3.7 \pm 0.9^{\circ} \mathrm{C} / \mathrm{h}$ was achieved by setting the flow rate of room temperature air to 14 $15 \mathrm{~L} / \mathrm{min}$. Similarly, in piglets, with the initiation of nasopharyngeal cooling with the same setting, the brain temperature decreased to $33.9 \pm 1.7{ }^{\circ} \mathrm{C}$ from baseline $\left(38.4 \pm 0.7{ }^{\circ} \mathrm{C}\right)$ which resulted in mean brain cooling rates of $4.5 \pm 1.2^{\circ} \mathrm{C} / \mathrm{h}$. The rabbits and piglets had an average body temperature of $37.5 \pm 0.8{ }^{\circ} \mathrm{C}$ and $38.2 \pm 0.6{ }^{\circ} \mathrm{C}$ (range $37.5-38.8{ }^{\circ} \mathrm{C}$ ), which was within the normal temperature range, respectively [25].

In the second series of experiments, we showed that SBC can be achieved more rapidly by blowing cold air $\left(\approx-7^{\circ} \mathrm{C}\right)$ at a flow rate of $14-15 \mathrm{~L} / \mathrm{min}$ into the nasal cavity; brain temperature in piglets and rabbits were reduced at mean rates of $5.2 \pm 1.9{ }^{\circ} \mathrm{C} / \mathrm{h}$

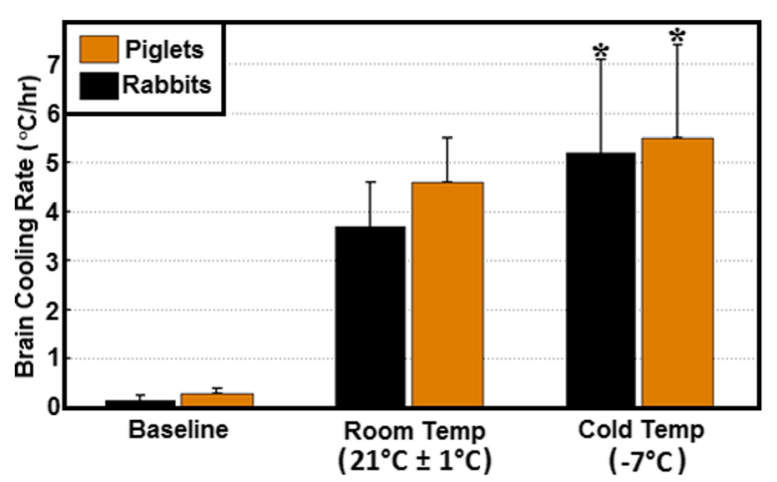

Fig. 4 Mean brain cooling rate with different nasopharyngeal cooling methods on rabbits and piglets. Asterisk signifies a statistically significant $(p<0.05)$ difference between cold temperature versus room temperature in the same species 
and $5.5 \pm 0.9^{\circ} \mathrm{C} / \mathrm{h}$, respectively. In rabbits, the maximum brain-esophageal temperature gradient of $-4.5{ }^{\circ} \mathrm{C}$ was reached about $50 \mathrm{~min}$ after the initiation of cooling and remained unchanged during the rest of nasopharyngeal cooling. Systemic adverse effects of hypothermia in general appear to be proportional to the degree of cooling [7]. Therefore, in order to minimize the complications associated with systemic hypothermia, the core body temperature was maintained above $36{ }^{\circ} \mathrm{C}$, which is within the normal temperature range in humans [26]. However, in piglets, the core temperature continued to drop till it reached the cooled brain temperature. The most likely explanation for this discrepancy is that in rabbits once the brain temperature stabilized after 60 min of nasopharyngeal cooling, the core temperature was maintained $>36{ }^{\circ} \mathrm{C}$ using recirculating heated water blankets and hot water gloves; however in piglets, their body was only covered with linen sheets and no external heating sources were utilized.

A temperature of $\sim-7{ }^{\circ} \mathrm{C}$ and a flow rate of $14-15 \mathrm{~L} / \mathrm{min}$ were chosen from the results of a small series of titration experiments in six pigs in which both temperature and flow rate were adjusted with the target of cooling the brain to $32-34{ }^{\circ} \mathrm{C}$ within 30 $45 \mathrm{~min}$. Although it is unlikely that air at subzero temperature will induce freezing damage to the mucosa and embedded blood vessels and nerves of the nasal cavity, we monitored the temperature inside the nasal cavity to avoid subzero temperature. A thermistor was placed at the tip of one of the two nasal catheters to measure the temperature inside the nasal cavity throughout the experiments. Even at a flow rate of $14-15 \mathrm{~L} / \mathrm{min}$ and a temperature of $\approx-7^{\circ} \mathrm{C}$, the air was warmed rapidly along the nasal catheters before reaching the nasopharyngeal tissue. An average temperature of about $6-7{ }^{\circ} \mathrm{C}$ was consistently measured with the catheter tip thermistor. In our previous study [27], we investigated whether there was any damage to the upper respiratory tract following $\sim 7 \mathrm{~h}$ cooling in three pigs, and as a result, no nasal or nasopharynx mucosal swelling, necrosis, or hemorrhages were revealed on MRI images. However, more detail histopathology examination may be necessary in future studies.

Many studies have been reported that hypothermia can induce metabolic disturbances and lower electrolyte levels during cooling, such as hypokalemia (serum potassium levels less than $3.5 \mathrm{mmol} / \mathrm{L}$ ) by a transcellular shift of potassium into the intracellular compartment $[28,29]$. Such electrolyte disorders can increase the risk of arrhythmias and other potentially harmful complications [30, 31]. Therefore, frequent measurement of electrolytes during cooling is necessary to guide the appropriate amount of replenishment due to the risk of rebound hyperkalemia, as potassium can move back out of the cells when the patient is rewarmed. However, contrary to hypokalemia during cooling, a gradual increase in serum potassium level (i.e., hyperkalemia) was observed in this study, which could be due to the anesthetic effects [32, 33]. Therefore, it might be worth trying different anesthetic induction agents in future studies. Moreover, nasopharyngeal cooling in both groups was initially associated with peripheral vasoconstriction, tachycardia, and increased cardiac output. However, a progressive decrease in temperature led to bradycardia, decreased cardiac output, and hypotension which are likely a combined effect of temperature reduction and general anesthesia [34].

There are some limitations/concerns that need to be addressed prior to clinical situations. First, there are several anatomical differences between these animal species and humans (e.g., cerebral blood flow, distance from the nasopharynx to the brain, size of the brain, and the area in which heat exchange is carried out). Piglets and rabbits differ 
considerably to humans or larger animals in their ratio between the size of their body weight and their brain. As such, the effectiveness of this approach on brain cooling might not be the same on larger mammals. Second, the infusion rate at which brain cooling was achieved (i.e., $15 \mathrm{~L} / \mathrm{min}$ ) may be different in humans. Third, in all of the experimental studies, anesthesia was maintained with $1-2 \%$ isoflurane until the end of the experiment without any remarkable changes in blood pressure, heart rate, or oxygen saturation. Isoflurane was used as the main anesthetic in the present study, as its administration is easy to apply and quick to control the level of anesthesia. This avoids problems associated with injectable anesthetics, such as a lack of agents to reverse their activity rapidly in case of overdose or possible side-effects. Isoflurane has been shown to influence systemic arterial blood pressure and cardiac output only to a minimal degree over several hours of induction [35]. Experiments in animals have shown that isoflurane has effects on cerebral blood flow $(\mathrm{CBF})$, cerebral metabolic rate for oxygen $\left(\mathrm{CMRO}_{2}\right)$, and intracranial pressure (ICP). Isoflurane reduces $\mathrm{CMRO}_{2}$ and causes a minimum to moderate increase in CBF and ICP [36, 37] which have limited its use as a sedative agent in the neurosurgical intensive care unit. In our group, we showed that a typical anesthetic induction dose of propofol reduces blood pressure by $\sim 30 \%$ when the anesthetic was switched from isoflurane to propofol [38]. A final concern with this study is that the brain temperature was measured at one position and therefore, no information was delivered about the homogeneity of regional brain temperature. However, in two experiments, the temperature gradient within the rabbit's brain, calculated as the difference between frontal and parietal lobes, was measured and was not more than $0.1{ }^{\circ} \mathrm{C}$. The only disadvantage experienced with the use of the vortex tube during experiments was the continuous noise of escaping air, which can be minimized by installing all components in a mobile enclosed cart, which is commercially available.

\section{Conclusion}

We have demonstrated that using the vortex tube allows initial rapid and specific brain cooling in rabbits. Moreover, comparing results between piglets and rabbits demonstrates that the lack of a carotid rete does not prevent specific cooling of the brain by means of the nasopharyngeal method. To evaluate the efficiency of the method and reproducibility of the cooling, we will switch to a large animal model, juvenile pigs, in our next set of experiments and explore maintenance of the brain-body temperature gradient for $6-7 \mathrm{~h}$ cooling and gradual rewarming rate $\left(0.25{ }^{\circ} \mathrm{C} / \mathrm{h}\right)$. In future studies, we will be blowing humidified air into nasal cavities and humidity will be measured and controlled inside of the nasal catheter right before nasal cavities. Histopathological studies on the lining of the nasal cavity will also be performed to demonstrate that there is no damage induced by blowing air for an extended period into the nostrils.

Acknowledgements

The authors would like to thank Laura Morrison and Jennifer Hadway for their help in conducting the animal experiments.

This study was sponsored by the Lawson Health Research Institute. 


\section{Authors' contributions}

$T-Y L, M F B$, and $L K$ conceived the project. T-YL and MFB designed and performed the experiments. MFB wrote the manuscript. T-YL edited and revised the manuscript. All authors reviewed and approved the final manuscript before submission.

\section{Ethics approval and consent to participate}

The protocol was approved by the Animal Use Subcommittee of the Canadian Council of Animal Care at Western University. This manuscript does not report on or involve the use of any human data.

\section{Competing interests}

MFB, LK, and T-YL are inventors on patent WO2015139142A1 describing the mammalian head cooling system and method.

\section{Publisher's Note}

Springer Nature remains neutral with regard to jurisdictional claims in published maps and institutional affiliations.

\section{Author details}

${ }^{1}$ Imaging Program, Lawson Health Research Institute, London, Ontario, Canada. ${ }^{2}$ Imaging Research Laboratories, Robarts Research Institute, 100 Perth Drive, P.O. Box 5015, London, Ontario N6A 5k8, Canada. ${ }^{3}$ Departments of Medical Imaging and Biophysics, The University of Western Ontario, London, Ontario, Canada.

\section{Received: 9 June 2018 Accepted: 21 October 2018}

\section{Published online: 01 November 2018}

\section{References}

1. Moore EM, Nichol AD, Bernard SA, Bellomo R (2011) Therapeutic hypothermia: benefits, mechanisms and potential clinical applications in neurological, cardiac and kidney injury. Injury 42(9):843-854

2. Lampe JW, Becker LB (2011) State of the art in therapeutic hypothermia. Annu Rev Med 62:79-93

3. Hassani $\mathrm{H}$, Meyer $\mathrm{S}$ (2010) Hypothermia for neuroprotection in adults after cardiopulmonary resuscitation. Am Fam Physician 82(5):477

4. Andrews PJ, Sinclair HL, Battison CG, Polderman KH, Citerio G, Mascia L, Harris BA, Murray GD, Stocchetti N, Menon DK et al (2011) European society of intensive care medicine study of therapeutic hypothermia (32-35 degrees C) for intracranial pressure reduction after traumatic brain injury (the Eurotherm3235Trial). Trials 12:8

5. Kuboyama K, Safar P, Radovsky A, Tisherman SA, Stezoski SW, Alexander H (1993) Delay in cooling negates the beneficial effect of mild resuscitative cerebral hypothermia after cardiac arrest in dogs: a prospective, randomized study. Crit Care Med 21(9):1348-1358

6. Nielsen N, Wetterslev J, Friberg H (2014) Targeted temperature management after cardiac arrest. N Engl J Med 370(14):1360

7. Schubert A (1995) Side effects of mild hypothermia. J Neurosurg Anesthesiol 7(2):139-147

8. Sarkar S, Barks JD (2010) Systemic complications and hypothermia. Semin Fetal Neonatal Med 15(5):270-275

9. Krieger DW, Yenari MA (2004) Therapeutic hypothermia for acute ischemic stroke: what do laboratory studies teach us? Stroke 35(6):1482-1489

10. Zenker W, Kubik S (1996) Brain cooling in humans--anatomical considerations. Anat Embryol (Berl) 193(1):1-13

11. Thoresen M, Hobbs CE, Wood T, Chakkarapani E, Dingley J (2009) Cooling combined with immediate or delayed xenon inhalation provides equivalent long-term neuroprotection after neonatal hypoxia-ischemia. J Cereb Blood Flow Metab 29(4):707-714

12. Busch HJ, Eichwede F, Fodisch M, Taccone FS, Wobker G, Schwab T, Hopf HB, Tonner P, Hachimi-Idrissi S, Martens P, et al (2010) Safety and feasibility of nasopharyngeal evaporative cooling in the emergency department setting in survivors of cardiac arrest. Resuscitation 81(8):943-949

13. Castren M, Nordberg P, Svensson L, Taccone F, Vincent IL, Desruelles D, Eichwede F, Mols P, Schwab T, Vergnion M, et al (2010) Intra-arrest transnasal evaporative cooling: a randomized, prehospital, multicenter study (PRINCE: Pre-ROSC IntraNasal Cooling Effectiveness). Circulation 122(7):729-736

14. Poli S, Purrucker J, Priglinger M, Sykora M, Diedler J, Rupp A, Bulut C, Hacke W, Hametner C (2014) Safety evaluation of nasopharyngeal cooling (RhinoChill(R)) in stroke patients: an observational study. Neurocrit Care 20(1):98-105

15. Fazel Bakhsheshi M, Keenliside L, Lee TY (2016) Rapid and selective brain cooling method using vortex tube: a feasibility study. Am J Emerg Med. https://doi.org/10.1016/j.ajem.2016.02.001

16. Jessen C (2001) Selective brain cooling in mammals and birds. Jpn J Physiol 51(3):291-301

17. McConaghy FF, Hales JR, Rose RJ, Hodgson DR (1995) Selective brain cooling in the horse during exercise and environmental heat stress. J Appl Physiol 79(6):1849-1854

18. Caputa M, Kamari A, Wachulec M (1991) Selective brain cooling in rats resting in heat and during exercise. J Therm Biol 16:19-24

19. Caputa M, Kadziela W, Narebski J (1977) Brain-cranial venous blood heat exchanger and hypertherrnia in rabbits. Bull Acad Polon Sci Ser Sci Biol 25:695-698

20. Bakhsheshi MF (2014) Nasopharyngeal method for selective brain cooling and development of a time-resolved nearinfrared technique to monitor brain temperature and oxidation status during hypothermia. Western University, PhD Thesis, Department Medical Biophysics, Western University, London

21. Bakhsheshi MF, Stewart EE, Tai JH, Morrison L, Keenliside L, Lee TY (2016) Efficacy of selective brain cooling using a nasopharyngeal method in piglets. Neurocrit Care 24(1):140-149

22. Bakhsheshi MF, Stewart EE, et al (2016) Efficacy of selective brain cooling using a nasopharyngeal method in piglets. Neurocrit Care 24(1):140-149.

23. Liew R, Zeegers JC, Kuerten JG, Michalek WR (2012) Maxwell's demon in the Ranque-Hilsch vortex tube. Phys Rev Lett 109(5):054503

24. Ahlborn B, Groves S (1997) Secondary flow in a vortex tube. Fluid Dyn Res 21:73-86 
25. Cross B (1996) The biology and medicine of rabbits and rodents, 4th ed. Can Vet J 37(12):759-760

26. Karakitsos D, Karabinis A (2008) Hypothermia therapy after traumatic brain injury in children. N Engl J Med 359(11): 1179-1180

27. Fazel Bakhsheshi M, Wang Y, Keenliside L, Lee TY (2016) A new approach to selective brain cooling by a Ranque-Hilsch vortex tube. Intensive Care Med Exp 4(1):32

28. Polderman KH, Peerdeman SM, Girbes AR (2001) Hypophosphatemia and hypomagnesemia induced by cooling in patients with severe head injury. J Neurosurg 94(5):697-705

29. Polderman KH, Herold I (2009) Therapeutic hypothermia and controlled normothermia in the intensive care unit: practical considerations, side effects, and cooling methods. Crit Care Med 37(3):1101-1120

30. Polderman $\mathrm{KH}$, van Zanten AR, Girbes AR (2003) The importance of magnesium in critically ill patients: a role in mitigating neurological injury and in the prevention of vasospasms. Intensive Care Med 29(7):1202-1203

31. Soliman HM, Mercan D, Lobo SS, Melot C, Vincent JL (2003) Development of ionized hypomagnesemia is associated with higher mortality rates. Crit Care Med 31(4):1082-1087

32. Singer M, Coluzzi F, O'Brien A, Clapp LH (2005) Reversal of life-threatening, drug-related potassium-channel syndrome by glibenclamide. Lancet 365(9474):1873-1875

33. Kersten JR, Schmeling TJ, Pagel PS, Gross GJ, Warltier DC (1997) Isoflurane mimics ischemic preconditioning via activation of K(ATP) channels: reduction of myocardial infarct size with an acute memory phase. Anesthesiology 87(2):361-370

34. Wong KC (1983) Physiology and pharmacology of hypothermia. West J Med 138(2):227-232

35. Szczesny G, Veihelmann A, Massberg S, Nolte D, Messmer K (2004) Long-term anaesthesia using inhalatory isoflurane in different strains of mice-the haemodynamic effects. Lab Anim 38(1):64-69

36. Scheller MS, Nakakimura K, Fleischer JE, Zornow MH (1990) Cerebral effects of sevoflurane in the dog: comparison with isoflurane and enflurane. Br J Anaesth 65(3):388-392

37. Scheller MS, Tateishi A, Drummond JC, Zornow MH (1988) The effects of sevoflurane on cerebral blood flow, cerebral metabolic rate for oxygen, intracranial pressure, and the electroencephalogram are similar to those of isoflurane in the rabbit. Anesthesiology 68(4):548-551

38. Bakhsheshi MF, Diop M, Morrison LB, St Lawrence K, Lee TY (2015) Coupling of cerebral blood flow and oxygen consumption during hypothermia in newborn piglets as measured by time-resolved near-infrared spectroscopy: a pilot study. Neurophotonics 2(3):035006

\section{Submit your manuscript to a SpringerOpen ${ }^{\circ}$ journal and benefit from:}

- Convenient online submission

- Rigorous peer review

- Open access: articles freely available online

- High visibility within the field

- Retaining the copyright to your article

Submit your next manuscript at $>$ springeropen.com 